What we can learn from published reports of euthanasia in persons with dementia: A reply to Marijnissen et al.

Scott Y H Kim MD, PhD, Marie E Nicolini MD, MSc , Dominic R Mangino MS, RRT, Raymond G De Vries PhD

PII: S1064-7481(20)30413-9

DOI: https://doi.org/10.1016/j.jagp.2020.07.005

Reference: AMGP 1535

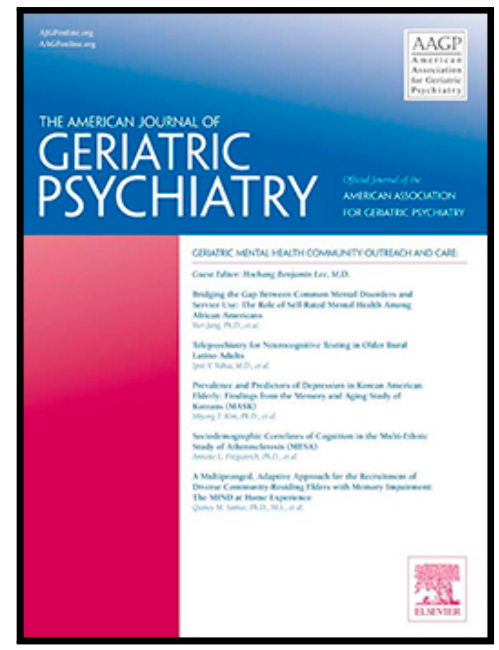

To appear in:

The American Journal of Geriatric Psychiatry

Received date:

27 May 2020

Revised date:

9 July 2020

Accepted date:

9 July 2020

Please cite this article as: Scott Y H Kim MD, PhD, Marie E Nicolini MD, MSc, Dominic R Mangino MS, RRT , Raymond G De Vries PhD, What we can learn from published reports of euthanasia in persons with dementia: A reply to Marijnissen et al., The American Journal of Geriatric Psychiatry (2020), doi: https://doi.org/10.1016/j.jagp.2020.07.005

This is a PDF file of an article that has undergone enhancements after acceptance, such as the addition of a cover page and metadata, and formatting for readability, but it is not yet the definitive version of record. This version will undergo additional copyediting, typesetting and review before it is published in its final form, but we are providing this version to give early visibility of the article. Please note that, during the production process, errors may be discovered which could affect the content, and all legal disclaimers that apply to the journal pertain.

C 2020 Published by Elsevier Inc. on behalf of American Association for Geriatric Psychiatry. 
What we can learn from published reports of euthanasia in persons with dementia:

\section{A reply to Marijnissen et al.}

Scott Y H Kim, MD, PhD ${ }^{1}$; Marie E Nicolini, MD, MSc ${ }^{1,2}$; Dominic R Mangino, MS, $\mathrm{RRT}^{1}$; Raymond G De Vries, $\mathrm{PhD}^{3,4}$

1. National Institutes of Health, Clinical Center, Department of Bioethics, Bethesda, MD, USA

2. Center for Biomedical Ethics and Law, KU Leuven, Leuven, Belgium

3. University of Michigan Medical School, Center for Bioethics and Social Sciences in Medicine, Ann Arbor MI

4. CAPHRI School for Public Health and Primary Care, Maastricht University, Maastricht, the Netherlands

\section{Corresponding Author:}

Scott Kim, MD, PhD

Department of Bioethics, Clinical Center

National Institutes of Health

10 Center Drive, 1 C118

Bethesda, MD 20892-1156

T 301.435.8706

scott.kim@nih.gov

The opinions are those of the authors and do not represent the views of the NIH, DHHS, or the US Government. 
We thank Marijnissen et al. ${ }^{1}$ for their thoughtful comments and an opportunity to provide additional context to our paper. ${ }^{2}$ Their letter, however, includes some errors and potentially misleading statements. They begin by asserting that we mischaracterized the EAS review process. They quote us as describing the review as "afterwards reviewing a self-report subjective report of the physician." ${ }^{1}$ What we actually wrote, which remains accurate, was: “...the retrospective oversight system relies on self-reports by physicians involved in the EAS process." $^{2}$

More concerning than this misquote is the picture of the EAS review process painted by the authors. It is misleading to say "by law, physicians ... are committing a criminal offense" and that they are then later "dismissed from criminal prosecution" ${ }^{1}$ as though the starting point is a presumption of prosecution. Yes, euthanasia/assisted suicide per se remains in the criminal code, but a doctor who performs it within 'due care' criteria is not committing a crime-a system like other jurisdictions', such as Canada's. ${ }^{3}$

It is not accurate to imply that there is a prosecutor hovering over the physician in each EAS case. Indeed, the court case mentioned by Marijnissen et al. was the very first time-in the nearly 50,000 cases of euthanasia since the 2002 law was enacted-that a prosecutor even initiated an investigation. ${ }^{4}$ This is because the intent of the law is to put the initial review of EAS cases "entirely outside the purview of the criminal justice authorities." ${ }^{5}(p .54)$ The EAS review system places great trust in physicians. We refer readers to our detailed study of the 'due care not met' cases for more details. ${ }^{4}$ 
As for the authors' second point, we explicitly stated in our paper, "the RTE does not publish all dementia EAS cases, limiting generalizability. Additionally, only completed EAS cases were studied."(p. 476) However, as we note, the RTE has published virtually all advance-request EAS cases, making our study nearly a census of that practice.

In regard to concurrent request EAS cases we analyzed, it may be useful to repeat what we wrote in our paper: "these published reports are the only contemporaneous accounts of dementia EAS with patient-level detail available" and that "the RTEs intend the published cases to serve educational, precedent setting functions." ${ }^{2}(p .476)$ Our analysis of concurrent request EAS primarily focused on the surprising finding that many of these cases describe persons who in fact have significant impairments. We considered the implications of doctors having to interpret patients' gestures, utterances, as well as their previous statements to make determinations about the patients' current capacity status. ${ }^{2}$ Here, the RTE's purpose of providing instruction is highly relevant: by showing that the RTE treats even these quite impaired patients as being fully competent, our analysis allows readers to evaluate the actual Dutch practice and its oversight.

It is surprising that Marijnissen et al's letter does not specifically engage with our analysis; they simply re-assert the RTE's claim that concurrent request EAS patients are in "the early stages of their dementia and fully competent..."1 They share the view of the RTE that one does not become a 'late stage' incompetent patient for purposes of requesting EAS until the dementia is 
so advanced that one is "not able to communicate regarding their request." ${ }^{1}$ But if one reads our analysis, it will become apparent that what we describe is the all too familiar complexity generated by progression of dementia beyond the early stages. As such, the concurrent cases we describe in the paper are not unusual and make implausible the claim that all cases of concurrent request EAS "were in the early stages of their dementia and fully competent with regard to their request for EAS." ${ }^{11}$ italics added]

The final section of their letter discusses a 2016 case (case 2016-85 in our paper; the letter mistakenly refers to it as a 2019 case) that ended up in the Dutch Supreme Court. Although Marijnissen et al.'s description of the case is helpful, readers will benefit from a fuller description. We refer them to our extended and detailed analysis of the case ${ }^{6}$ and the debate regarding the rulings. ${ }^{7,8}$

As the practice of EAS in persons with dementia obviously remains controversial, we believe that delving into actual patient-level descriptions of the practice is crucial. Our work suggests that when this is done, it reveals a missing question in the debate: is the boundary between advance request and concurrent request EAS in persons with dementia as obvious as it is assumed to be? 
1. Marijnissen R, Schoevers R, Oude Voshaar R. Commentary letter to the editor on the study of Mangino et al: euthanasia and assisted suicide of persons with dementia. Am J Geriatr Psychiatry. 2020.

2. Mangino DR, Nicolini ME, De Vries RG, Kim SYH. Euthanasia and Assisted Suicide of Persons With Dementia in the Netherlands. Am J Geriatr Psychiatry. 2020;28(4):466477.

3. Bill C-14. An Act to amend the Criminal Code and to make related amendments to other Acts (medical assistance in dying). https://www.parl.ca/DocumentViewer/en/421/bill/C-14/royal-assent.

4. Miller DG, Kim SYH. Euthanasia and physician-assisted suicide not meeting due care criteria in the Netherlands: a qualitative review of review committee judgements. BMJ Open. 2017;7(e017628).

5. Griffiths J, Weyers H, Adams M. Euthanasia and Law in Europe. Oxford and Portland, OR: Hart Publishers; 2008.

6. Miller DG, Dresser R, Kim SYH. Advance euthanasia directives: a controversial case and its ethical implications. J Med Ethics. 2018;45(2):84-89.

7. Asscher ECA, van de Vathorst S. First prosecution of a Dutch doctor since the Euthanasia Act of 2002: what does the verdict mean? Journal of Medical Ethics. 2019;46(2):71-75.

8. Hughes JA. Advance euthanasia directives and the Dutch prosecution. Journal of Medical Ethics. 2020:medethics-2020-106131. 